\title{
RUNX3 copy number predicts the development of UC-associated colorectal cancer
}

\author{
TOSHIAKI WATANABE ${ }^{1}$, TAKASHI KOBUNAI $^{1,2}$, HIROKI IKEUCHI $^{3}$, YOKO YAMAMOTO ${ }^{1}$, \\ KEIJI MATSUDA ${ }^{1}$, SOICHIRO ISHIHARA ${ }^{1}$, KEIJIRO NOZAWA ${ }^{1}$, HISAE IINUMA ${ }^{1}$, \\ TAKAMITSU KANAZAWA ${ }^{4}$, TOSHIAKI TANAKA ${ }^{4}$, TADASHI YOKOYAMA ${ }^{4}$, \\ TSUYOSHI KONISHI ${ }^{4}$, KIYOSHI ESHIMA ${ }^{2}$, YOICHI AJIOKA ${ }^{5}$, TOSHIFUMI HIBI ${ }^{6}$, \\ MAMORU WATANABE ${ }^{7}$, TETSUICHIRO MUTO ${ }^{8}$ and HIROKAZU NAGAWA ${ }^{4}$
}

\author{
${ }^{1}$ Department of Surgery, Teikyo University School of Medicine, 2-11-1 Kaga, Itabashi-ku, Tokyo 173-8605; \\ ${ }^{2}$ Tokushima Research Center, Taiho Pharmaceutical Co., Ltd., 224-2 Ebisuno, Hiraishi, Kawauchi-cho, Tokushima 771-0194; \\ ${ }^{3}$ Second Department of Surgery, Hyogo College of Medicine, 1-1 Mukogawa-cho, Nishinomiya, Hyogo 663-8501; \\ ${ }^{4}$ Department of Surgical Oncology, University of Tokyo, 7-3-1 Hongo, Bunkyo-ku, Tokyo 113-8655; \\ ${ }^{5}$ Department of Pathology, Niigata Univeristy, 754 Ichibancho, Asahimachidori, Niigata 951-8510; \\ ${ }^{6}$ Division of Gastroenterology, Department of Internal Medicine, Keio University School of Medicine, Tokyo 160-8582; \\ ${ }^{7}$ Department of Gastroenterology, Tokyo Medical and Dental Univeristy, 1-5-45 Yushima, Bunkyo-ku, Tokyo 113-8501; \\ ${ }^{8}$ The Cancer Institute Hospital of Japanese Foundation for Cancer Research, 3-10-6 Ariake, Kotoh-ku, Tokyo 135-8550, Japan
}

Received July 12, 2010; Accepted September 2, 2010

DOI: 10.3892/ijo_00000839

\begin{abstract}
RUNX3 is a tumour suppressor gene that plays an important role in the development of various cancers. The present study aimed to compare RUNX3 mRNA expression levels and DNA copy numbers in the non-neoplastic rectal mucosa between ulcerative colitis (UC) patients with and without UC-associated colorectal cancer (UC-Ca). We further aimed to build a predictive model of the development of UC-Ca based on the RUNX3 DNA copy number. RUNX3 mRNA expression levels were quantified by RT-PCR. The hypermethylation and DNA copy number of $R U N X 3$ were also determined. Thirty-five UC patients were examined, 17 of whom had UC-Ca (UC-Ca group) and 18 who did not (UCNonCa group). The UC-Ca group had significantly lower mRUNX3 expression levels and smaller DNA copy numbers than the UC-NonCa group ( $\mathrm{p}=0.04, \mathrm{p}=0.0016$, respectively). $R U N X 3$ expression levels correlated with DNA copy numbers. Classification of the UC-Ca and UC-NonCa group based on DNA copy number gave an accuracy of $82.9 \%$. RUNX3 expression levels in the non-neoplastic rectal mucosa was significantly decreased in the UC-Ca group and it is
\end{abstract}

Correspondence to: Dr Toshiaki Watanabe, Department of Surgery, Teikyo University School of Medicine, 2-11-1 Kaga, Itabashi-ku, Tokyo 173-8605, Japan

E-mail: toshwatanabe@yahoo.co.jp

Key words: ulcerative colitis, colorectal cancer, RUNX3, copy number, prediction suggested that this was attributable to the decrease in RUNX3 DNA copy number. The present predictive model may be useful in the selection of high risk UC-Ca patients and to improve the efficacy of surveillance colonoscopy. The present study suggests that $R U N X 3$ might play an important role in the development of UC-Ca.

\section{Introduction}

Patients with long-standing ulcerative colitis (UC) have an increased risk of developing colorectal cancer. This risk increases with the duration of the disease, and the estimated cumulative risk of UC-associated colorectal cancer (UC-Ca) 30 years after the onset of UC has been reported by metaanalysis to be $18 \%$ (1). Therefore, for the early detection of neoplastic lesions, surveillance colonoscopy is recommended for patients whose duration of the disease is 7-8 years or more (2-4). However, to further improve the efficacy of surveillance, new markers to predict the development of UC-Ca are urgently needed.

Previous studies have shown that patients with UC-Ca have widespread genetic alterations in the non-neoplastic colonic mucosa, suggesting that such changes might be effective predictors of UC-Ca development (5-8). Indeed, we previously demonstrated this by DNA microarray gene expression analysis (9). However, to date, specific molecular markers that can be used in clinical settings have not been established.

RUNX3 belongs to the Runt domain family of transcription factors, and is involved in T-cell differentiation, the TGF- $\beta$ induced tumour suppressor pathway $(10,11)$ and is a known tumour suppressor gene in gastric cancer (12). Previous studies 
reported that alterations in $R U N X 3$ gene expression were present in various types of cancer including breast, lung, hepatocellular, prostate, bile duct, pancreatic and colon cancers (10-12). Studies have also shown that RUNX3 gene expression levels are influenced by the hypermethylation of CpG islands in the RUNX3 promoter region (13-19). On the other hand, a recent report suggested a role for $R U N X 3$ in UC susceptibility, the development of colitis and gastric mucosal hyperplasia $(20,21)$. Weersma et al showed that RUNX3 mRNA expression is increased in the colonic mucosa of UC patients compared with controls (20).

In our previous microarray analysis, $R U N X 3$ was expressed at lower levels in the non-neoplastic mucosa of patients with UC-Ca compared to those without (9). However, microarray analysis is known to lack reproducibility as a means of quantitative analysis of gene expression. In order to accurately validate gene expression levels, it requires verification by an alternative quantitative approach, such as real-time PCR $(22,23)$. Another problem with microarray analysis is the large number of genes used in prediction models. In our previous model, gene expression levels of 72 genes were examined to predict the development of UC-Ca. Because of these problems, the use of microarrays in clinical practice remains limited, and recent studies have shown that RT-PCR analyses of a small number of selected genes are useful in predicting the outcome of patients in various diseases $(22,23)$.

Therefore, in the present study, we aimed to confirm the decreased expression of $R U N X 3$ by RT-PCR in patients with UC-Ca. We also analysed possible mechanisms for decreased $R U N X 3$ expression by examining the hypermethylation of $\mathrm{CpG}$ islands in the promotor region, and RUNX3 DNA copy numbers. Lastly, we aimed to use this copy number to establish a predictive model of patients with UC-Ca.

\section{Materials and methods}

Patients and samples. Thirty-five UC patients were examined. Informed consent was obtained from all patients for the collection of specimens, and the study protocol was approved by the local Ethics Committee. All UC patients had total colitis and their disease had persisted for more than seven years; they were therefore considered to be at high risk of cancer and/or dysplasia development. Among the 35 UC patients, 17 had UC-associated adenocarcinoma (UC-Ca group) and 18 had no neoplastic lesions (UC-NonCa group). Patient characteristics are shown in Table I.

In all UC-Cases, specimens were obtained from nonneoplastic rectal mucosa for DNA and RNA extraction (Fig. 1). Samples were taken either from surgically resected specimens or during surveillance colonoscopic examination. Samples were snap-frozen in liquid nitrogen and stored at $-80^{\circ} \mathrm{C}$ until use. Paralleled tumour specimens were formalin-fixed and paraffin-embedded for histological examination as described previously (24). Microscopic examination of rectal mucosa in UC patients verified that no neoplastic cells were present in any of the samples.

RNA isolation and RT-PCR. Total RNA was isolated from frozen samples using the RNeasy Mini kit (Qiagen, Valencia, CA). Gene expression levels were determined using TaqMan real-time PCR (Applied Biosystems, Foster City, CA) as described previously (Fig. 1) (25). First-strand cDNA was synthesized from total RNA using the High Capacity cDNA Archive kit (Applied Biosystems) in $50 \mu 1$ reactions using cDNA samples for TaqMan real-time PCR analysis according to the manufacturer's instructions. cDNA (10 ng/ $\mu \mathrm{l})$ was added to $9.15 \mu 1$ RNase-free water, $12.5 \mu 12 \times$ TaqMan Universal PCR Master Mix (Applied Biosystems) and $1.25 \mu 1$ 20 x Primer Probe mix. ACTB (actin, B) was used as the endogenous control gene (Applied Biosystems). Assay IDs were Hs00231709_m1 and Hs99999903_m1 for RUNX3 and ACTB, respectively. PCR amplification was carried out using the Prism 7900HT Sequence Detection System (Applied Biosystems) under the following thermal cycler conditions: $2 \mathrm{~min}$ at $50^{\circ} \mathrm{C}$ and $10 \mathrm{~min}$ at $94.5^{\circ} \mathrm{C}$ for 40 cycles $(30 \mathrm{sec}$ at $97^{\circ} \mathrm{C}$ and $1 \mathrm{~min}$ at $59.7^{\circ} \mathrm{C}$ ). Relative RUNX3 gene expression was calculated by comparing the $\delta \mathrm{CT}$ values as previously described (26).

Genomic DNA preparation and RUNX3 methylation-specific $P C R$. Hypermethylation of the promoter region of the RUNX3 gene was determined by methylation-specific PCR. Genomic DNA was extracted using the QIAAMP DNA mini kit (Qiagen), according to the manufacturer's instructions. Bisulfite conversion of DNA samples was carried out essentially as described and was based on the principle that treatment of DNA with bisulfite would result in the conversion of unmethylated cytosine residues into uracil. Methylated cytosine residues, on the other hand, would remain unchanged (19). Thus, the DNA sequences of methylated and unmethylated genomic regions following bisulfite conversion would be different and distinguishable by sequence-specific PCR primers.

Bisulfite conversion was carried out using an EZ DNA methylation kit (ZYMO research, Orange, CA). DNA $(2 \mu \mathrm{g})$ was treated with sodium bisulfite following the manufacturer's recommendations and resuspended in a total volume of $10 \mu 1$. Hypermethylated DNA treated with Sss I and normal genomic DNA were used as methylation-positive and -negative control samples, respectively, in the following PCR assay: sense and antisense primers for the bisulfiteconverted methylated sequence were: mRUNX3-F (5'-TTA CGA GGG GGG GTC GTA CGC GGG-3') and mRUNX3-R (5'-AAA ACG ACC GAC GCG AAC GCC TCC-3') respectively. Sense and antisense primers for the bisulfite-converted unmethylated sequence were: uRUNX3-F (5'-TTA TGA GGG GTG GTT GTA TGT GGG-3') and uRUNX3-R (5'-AAA ACA ACC AAC ACA AAC ACC TCC-3'), respectively (19).

Real-time PCR was performed on a PRISM 7900 sequence detector (Applied Biosystems) using a QuantiTect SYBR Green kit (Qiagen). Conditions for quantitative PCR were as follows: one cycle at $94^{\circ} \mathrm{C}$ for $15 \mathrm{~min}, 45$ cycles at $94^{\circ} \mathrm{C}$ for $20 \mathrm{sec}, 56^{\circ} \mathrm{C}$ for $20 \mathrm{sec}$, and $70^{\circ} \mathrm{C}$ for $30 \mathrm{sec}$. The methylation status was judged from the calculated delta $\mathrm{Ct}$ value derived from the methylated and unmethylated sequence primer CT values.

Genomic DNA preparation and quantitative real-time PCR for determination of the RUNX3 DNA copy number. The $R U N X 3$ DNA copy number was determined by real-time PCR. 
Table I. Characteristics of patients.

\begin{tabular}{lcc}
\hline Characteristic & $\begin{array}{c}\text { CUC-Ca group } \\
(\mathrm{n}=17)\end{array}$ & $\begin{array}{c}\text { UC-NonCa group } \\
(\mathrm{n}=18)\end{array}$ \\
\hline
\end{tabular}

Age at biopsy (years)

$$
\text { Mean, SD }
$$

$54.3(34-70), 10.5$

Age at UC diagnosis (years)

$$
\text { Mean, SD }
$$

Gender

Male

Female

Duration of disease (years)

Mean, SD

Extent of UC

Total colitis

Left-sided colitis

Proctosigmoiditis

Proctitis

Inflammation

None

Mild

Moderate

Severe

Medication

Mesalamine

Corticosteroids 3

6MP/AZA

CSA

PSC

Present

Not present

17.7 (9-29), 6.8
$48.8(25-70), 11.8$

NS

NS

$31.4(15-55), 9.8$

NS

10

8

NS

$14.8(9-25), 6.9$

NS

16

2

0

0

NS

3

12

3

0

NS

11

2

0

NS

$\mathrm{SD}$, standard deviation; UC, ulcerative colitis; 6MP/AZA, 6-mercaptopurine/azathioprine; CSA, cyclosporin A; PSC, primary sclerosing cholangitis.

Genomic DNA was extracted from samples using the QIAAMP DNA mini kit (Qiagen) as before. Quantitative real-time PCR was performed on a PRISM 7900 sequence detector with a QuantiTect SYBR Green kit as before. We quantified the DNA by comparing the target locus to the reference Line-1, a repetitive element for which copy numbers per haploid genome are similar among all human normal and neoplastic cells. The relative target copy number level was also normalized to normal human genomic DNA as a calibrator. Copy number changes of the target gene relative to Line- 1 and the calibrator were determined using the formula $\left(\mathrm{T}_{\text {target }} / \mathrm{T}_{\text {Line- } 1}\right) /\left(\mathrm{C}_{\text {target }} / \mathrm{C}_{\text {Line- } 1}\right)$, where $\mathrm{T}_{\text {target }}$ and $\mathrm{T}_{\text {Line-1 }}$ are quantities from tumour DNA using target and Line-1, and $\mathrm{C}_{\text {target }}$ and $\mathrm{C}_{\text {Line- } 1}$ are quantities from the calibrator using target and Line-1. PCRs for each primer set were performed in triplicate or more, and mean values and standard deviations reported $(19,26)$.
Conditions for quantitative PCR were as above. At the end of the PCR reaction, samples were subjected to melting analysis to confirm amplicon specificity. PrimerExpress software, ver.2.0 was used to design the primers to span a 200 bp non-repetitive region, and primers were then synthesized by Operon Biotechnologies Inc. (Tokyo, Japan). The primer set was subsequently compared with the human genome using a basic local alignment search tool algorithm to determine its uniqueness. Primer sequences for RUNX3 are: Forward primer (intron 3), 5'-CCAACCACCTGCCTCT ATTCC-3'; Reverse primer (exon 4), 5'-TTGGTGAACACA GTGATGGTCA-3'.

Prediction of UC-associated neoplasm development by RUNX3 mRNA expression and DNA copy number. Areas under the receiver operator characteristic (ROC) curve (AUCs) were 


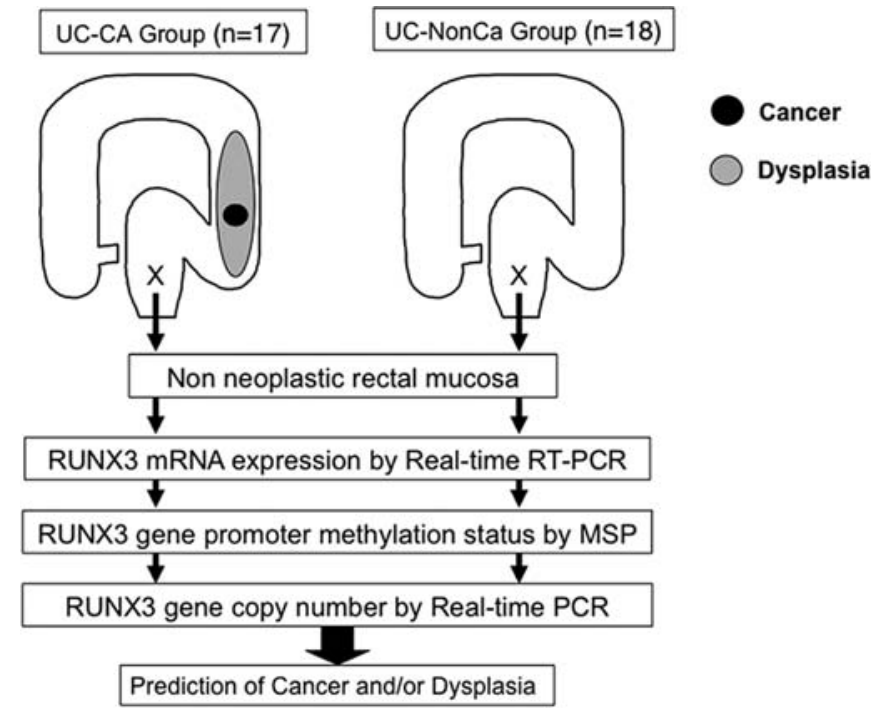

Figure 1. Sample collection and data analysis procedure. Samples were obtained from non-neoplastic rectal mucosa for RNA and DNA extraction. $R U N X 3$ mRNA expression level, hypermethylation of $R U N X 3$ promotor region and $R U N X 3$ DNA copy number were compared between UC-Ca and UC-NonCa groups.

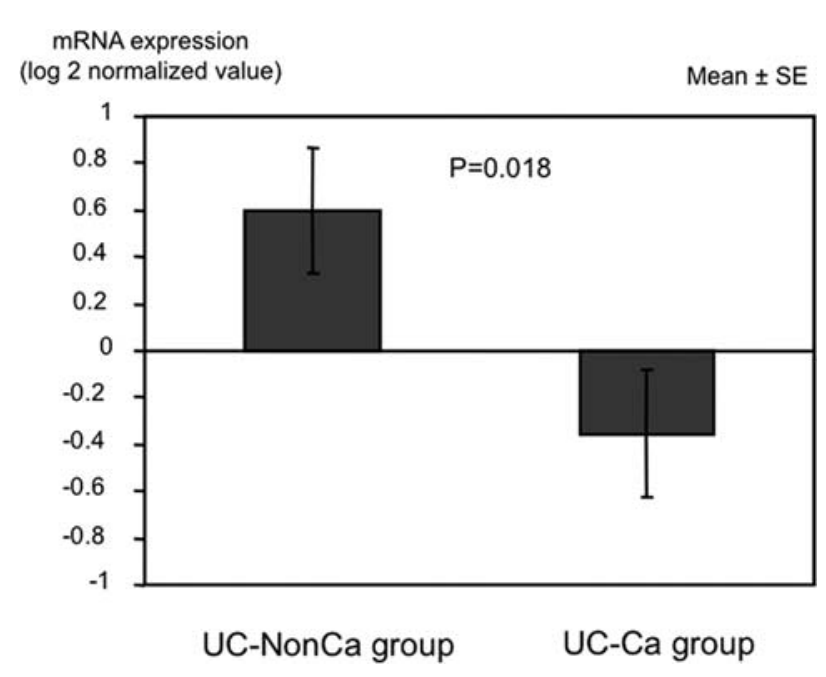

Figure 2. Mean mRNA expression of RUNX3. UC-NonCa group showed significantly higher $R U N X 3$ mRNA expression level than UC-Ca group ( $\mathrm{p}=0.018)$. Vertical axis shows normalized RUNX3 mRNA expression level. (A bar indicates standard deviation).

Table II. Methylation status of RUNX3 gene promoter region.

\section{No. of cases with \\ hypermethylation \\ No. of cases without
hypermethylation}

17

0

$(\mathrm{n}=17)$

0

0

18

UC-NonCa group

$(\mathrm{n}=18)$
Frequency of hypermethylation $(\%)$ calculated according to expression level or copy number for the ability of the logistic regression models to differentiate between UC-Ca and UC-NonCa patients. The predictive accuracy was determined by measuring the specificity, sensitivity, and area under the ROC curve. A predictive model with an ROC of $\geq 0.7$ is considered to have good discrimination, and an area under the ROC curve of 0.5 is equivalent to a 'coin toss'.

Statistical analysis. Associations between RUNX3 gene expression, promoter methylation, DNA copy number and clinical outcomes were tested using unpaired t-tests, generalized logistic model analysis or Fisher's exact test, as appropriate. Data were analyzed using JMP ver 5.0 software (SAS Institute, Tokyo).

\section{Results}

mRNA expression level by RT-PCR analysis. Gene expression levels of RUNX3 were significantly lower (1.9-fold) in the UC-Ca group compared with the UC-NonCa group $(\mathrm{p}=0.018)$ (Fig. 2). Mean Log2-normalized mRNA expression level for
UC-Ca group and UC-NonCa group was -0.35 and 0.6 , respectively.

Methylation status of RUNX3 gene promoter region. There was no significant difference in the methylation status of the $R U N X 3$ gene promoter region, with neither group showing hypermethylation (Table II).

DNA copy number of RUNX3. The mean copy number of $R U N X 3$ was significantly greater in the UC-NonCa group compared with the UC-Ca group (3.04 vs. 1.99, $\mathrm{p}=0.0016$ ) (Fig. 3).

mRNA expression level and DNA copy number of RUNX3. mRNA expression levels were then examined according to DNA copy number. The standard deviation of the RUNX3 copy number of non-neoplastic tissue adjacent to sporadic CRC tumours was 0.1 (data not shown), so we determined the cut-off value for copy number gain as $2.2(2.0+2 \mathrm{x} \mathrm{SD})$. Samples were divided into a high copy number $(>2.2)$ or low copy number $(\leq 2.2)$ group. The RUNX3 mRNA level was significantly higher in the high copy number group compared 


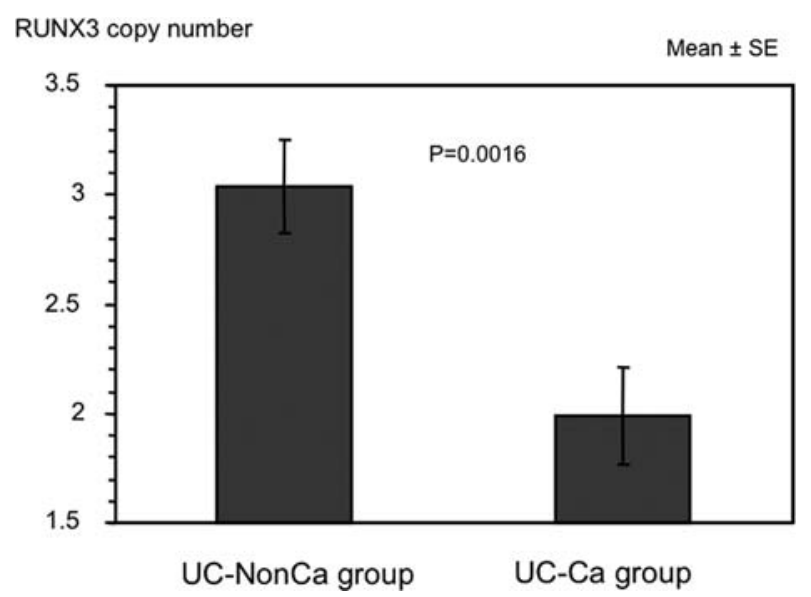

Figure 3. RUNX3 DNA copy number. UC-NonCa group showed significantly higher $R U N X 3$ DNA copy number than UC-Ca group (3.04 vs. 1.99, $\mathrm{p}=0.0016)$.

mRNA expression

( $\log 2$ normalized value) Mean \pm SE

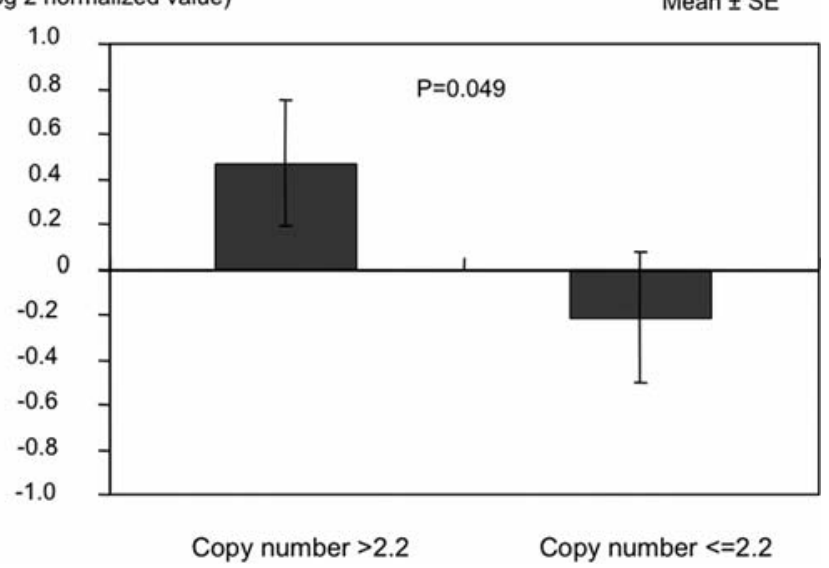

Figure 4. RUNX3 mRNA expression level and DNA copy number. High copy number group (>2.2) showed significantly higher mRNA expression level than low copy number group $(\leq 2.2)(\mathrm{p}=0.049)$.

to the low copy number group ( $\mathrm{p}=0.049)$ (Fig. 4). Mean Log2-normalized mRNA expression level for the high copy number group and the low copy number group was 0.47 and -0.21 , respectively.

Prediction of UC-associated neoplasm development by RUNX3 $m R N A$ level and DNA copy number. ROC analysis against UC-associated neoplasms revealed the AUC to be 0.74 and the copy number to be 0.85 (Fig. 5). To maximize sensitivity and specificity, we set the cut-off points as 0.027 and 2.06 for mRNA and DNA copy number, respectively. Using mRNA expression data, we were able to predict the development of UC-associated neoplasms with an accuracy of $74.3 \%$. The sensitivity, specificity, positive predictive value (PPV) and negative predictive value (NPV) were $76.5 \%, 72.2 \%, 72.2 \%$ and $76.5 \%$, respectively. There were nine misclassifiers: five in the UC-Ca group and four in the UC-NonCa group. Using

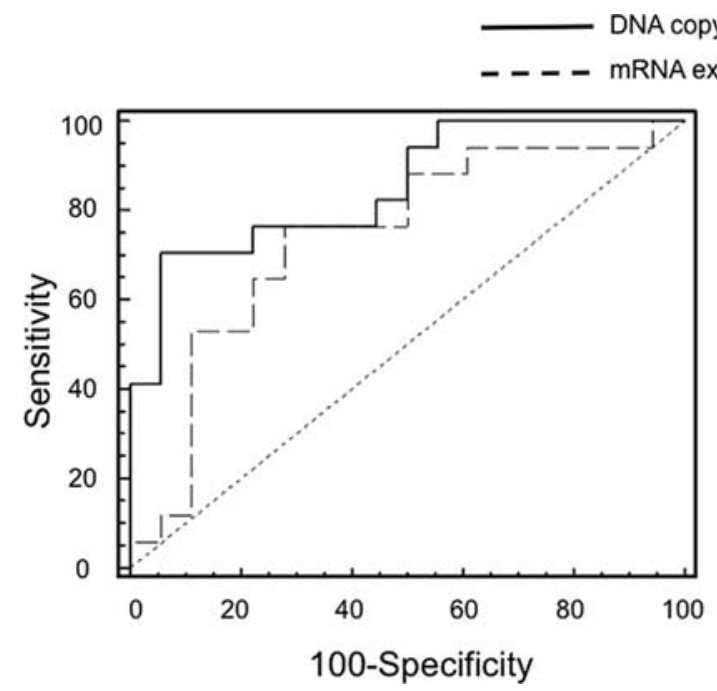

Figure 5. ROC curve for UC-Cancer prediction model based on RUNX3 mRNA expression and DNA copy number. Predicted probability of UCassociated cancer computed from logistic regression models including RUNX3 mRNA and DNA copy number. Specificity and sensitivity computed at each possible cut-off on predicted probability for two models. AUC values compared for two models.

DNA copy number data, we were able to predict the development of UC-associated neoplasms with an accuracy of $82.9 \%$. The sensitivity, specificity, PPV and NPV were $70.6 \%, 94.4 \%, 92.3 \%$ and $77.3 \%$, respectively. There were six misclassifiers: one in the UC-Ca group and five in the UC-NonCa group.

\section{Discussion}

In the current analysis of $R U N X 3$ expression in non-neoplastic rectal mucosa of UC patients, we were able to show that nonUC-Ca patients have significantly higher RUNX3 mRNA expression levels than UC-Ca patients. Increased DNA copy numbers of RUNX3 are a plausible mechanism for this change. Based on the DNA copy number, we were able to predict the development of UC-associated neoplasms with an accuracy of $82.9 \%$. The present model may enable more efficacious surveillance for UC patients by selecting high risk UC-Ca patients.

In UC-carcinogenesis, it is suggested that there is a field effect of chronic inflammation with a need for constantly increased re-epithelialisation and the suppression of cell cycle-regulating proteins, which may make genes susceptible to genetic damage. Indeed, previous studies have shown that specific gene alteration is already present in the non-neoplastic mucosa of UC-CA patients (5-8). However, to date, RUNX3 has not been identified as one of these genes. This is the first study to show altered RUNX3 expression levels in UC-Ca patients. RUNX3 expression is decreased in various cancers, (10-12) and was significantly decreased in UC-Ca patients compared with UC-NonCa patients in the present study. From these results, it is difficult to conclude that there is a causal relationship between $R U N X 3$ expression levels and the development of UC-Ca because there is no concrete evidence to support this hypothesis. However, considering that RUNX3 
is a tumor suppressor gene, decreased expression of RUNX3 may help to increase the risk of developing UC-Ca in longstanding UC patients.

Next, we examined the mechanisms of increased $R U N X 3$ expression in UC-NonCa patients. Previous studies have shown that hypermethylation plays an important role in controlling RUNX3 mRNA expression levels in various cancers including gastric cancer (13-19). Therefore, we first examined the hypermethylation of $\mathrm{CpG}$ islands in the promotor region of RUNX3. However, we failed to show any relation between hypermethylation status and $R U N X 3$ expression level because not a single case in either UC-Ca or UC-NonCa group showed the hypermethylation in $R U N X 3$ promoter DNA.

Recently, DNA copy number has gained attention as a possible mechanism for altering gene expression in various diseases $(27,28)$. Copy number variations may be either inherited or caused by de novo mutations and can influence gene expression $(28,29)$. In inflammatory bowel disease, changes in the DNA copy number have been reported in Crohn's disease. Fellermann et al reported that changes in the human $B$-defensin 2 gene copy number at the $B$-defensin locus predisposes individuals to Crohn's disease, most likely through diminished $B$-defensin expression (27). We therefore focused on DNA copy number as a possible regulator of RUNX3 mRNA expression and found that the UC-NonCa group had both higher copy numbers and RUNX3 expression levels than the UC-Ca group. These results suggest that increased expression of $R U N X 3$ mRNA in UC-NonCa patients might be attributable to the increased $R U N X 3$ DNA copy number. It is not known when the copy number changes occurred in UC-NonCa patients, but considering that the risk of UC-Ca increases with the duration of disease, we speculate that copy number changes might be acquired as de novo mutations during the long period of disease duration.

An important clinical implication of the present study is the prediction of patients at a higher risk of developing UC-Ca. In predicting the development of UC-associated neoplasm, we used mRNA expression level and DNA copy number. Although ROC analysis showed a higher AUC for DNA copy number $(0.85)$ than mRNA expression level $(0.74)$, the difference did not reach statistical significance and seemed to be attributable to a comparatively small number of cases. In fact, the overall predictive accuracy was higher by DNA copy number $(82.9 \%)$ than mRNA expression level (74.3\%), suggesting that RUNX3 DNA copy number is a more efficacious predictive marker than mRNA expression level. The accuracy level in the present model was not as high as our previous DNA microarray study, which showed a $98.1 \%$ accuracy rate, but required 40 genes to achieve this prediction accuracy. On the other hand, the present study only assessed $R U N X 3$ DNA copy number, so is a more cost-effective method and is easier to apply in clinical settings.

One limitation of the present study is that because of a comparatively small number of patients, we could not validate the accuracy of the predictive model. To further confirm its accuracy, the RUNX3 DNA copy number should be validated by testing at another institution, preferably with a prospective study of a larger number of patients. The second point is that RUNX3 expression levels are influenced by the degree of inflammation (20) which cannot be excluded from influencing the current results. However, in the present study, UC patients with active inflammation were excluded from analysis. Finally, the precise mechanism of action of RUNX3 has not been fully clarified, and analysis of this would greatly contribute to our understanding of the mechanisms of UC-Ca.

In conclusion, patients without UC-Ca showed higher expression of RUNX3 than those with UC-Ca. We show that this increase could have been caused by an increase in RUNX3 DNA copy number. Furthermore, using the RUNX3 copy number, we were able to predict patients with and without UC-Ca with an accuracy of $80 \%$, and suggest that this predictive model may be useful in detecting patients at high risk of developing UC-Ca, thereby increasing the efficacy of surveillance colonoscopy for UC patients.

\section{Acknowledgements}

This study was supported by a Grant-in-Aid for Scientific Research from the Ministry of Education, Culture, Sports, Science, and Technology of Japan and for Intractable Diseases, the Health and Labour Sciences Research Grants from Ministry of Health, Labor and Welfare of Japan. The authors are indebted to Eriko Hashimoto and Riyo Kakimoto for technical and secretarial support.

\section{References}

1. Eaden JA, Abrams KR and Mayberry JF: The risk of colorectal cancer in ulcerative colitis: a meta-analysis. Gut 48: 526-535, 2001.

2. Winawer S, Fletcher R, Rex D, et al: Gastrointestinal Consortium Panel: Colorectal cancer screening and surveillance: clinical guidelines and rationale-Update based on new evidence. Gastroenterology 124: 544-560, 2003.

3. Riddell RH, Goldman H, Ransohoff DF, et al: Dysplasia in inflammatory bowel disease: standardized classification with provisional clinical applications. Hum Pathol 14: 931-968, 1983.

4. Hata K, Watanabe T, Kazama S, et al: Earlier surveillance colonoscopy programme improves survival in patients with ulcerative colitis associated colorectal cancer: results of a 23year surveillance programme in the Japanese population. $\mathrm{Br} \mathrm{J}$ Cancer 89: 1232-1236, 2003.

5. Hsieh CJ, Klump B, Holzmann K, Borchard F, Gregor M and Porschen R: Hypermethylation of the p16INK4a promoter in colectomy specimens of patients with long-standing and extensive ulcerative colitis. Cancer Res 58: 3942-3945, 1998.

6. Sato F, Harpaz N, Shibata D, et al: Hypermethylation of the p14(ARF) gene in ulcerative colitis-associated colorectal carcinogenesis. Cancer Res 62: 1148-1151, 2002.

7. Issa JP, Ahuja N, Toyota M, Bronner MP and Brentnall TA: Accelerated age-related $\mathrm{CpG}$ island methylation in ulcerative colitis. Cancer Res 61: 3573-3577, 2001.

8. Brentnall TA, Crispin DA, Bronner MP, et al: Microsatellite instability in nonneoplastic mucosa from patients with chronic ulcerative colitis. Cancer Res 56: 1237-1240, 1996.

9. Watanabe $\mathrm{T}$, Kobunai $\mathrm{T}$, Toda $\mathrm{E}$, et al: Gene expression signature and the prediction of ulcerative colitis-associated colorectal cancer by DNA microarray. Clin Cancer Res 13: 415420, 2007.

10. Lau QC, Raja E, Salto-Tellez M, et al: RUNX3 is frequently inactivated by dual mechanisms of protein mislocalization and promoter hypermethylation in breast cancer. Cancer Res 66: 6512-6520, 2006.

11. Fukamachi $\mathrm{H}$ and Ito $\mathrm{K}$ : Growth regulation of gastric epithelial cells by RUNX3. Oncogene 23: 4330-4335, 2004.

12. Li QL, Ito K, Sakakura C, et al: Causal relationship between the loss of RUNX3 expression and gastric cancer. Cell 109: 113-124, 2002. 
13. Kim TY, Lee HJ, Hwang KS, Lee M, Kim JW, Bang YJ and Kang GH: Methylation of RUNX3 in various types of human cancers and premalignant stages of gastric carcinoma. Lab Invest 84: 479-484, 2004.

14. Suzuki M, Shigematsu H, Shames DS, et al: DNA methylationassociated inactivation of TGFbeta-related genes DRM/ Gremlin, RUNX3, and HPP1 in human cancers. Br J Cancer 93: 1029-1037, 2005.

15. Wada M, Yazumi S, Takaishi S, et al: Frequent loss of RUNX3 gene expression in human bile duct and pancreatic cancer cell lines. Oncogene 23: 2401-2407, 2004.

16. Li QL, Kim HR, Kim WJ, et al: Transcriptional silencing of the RUNX3 gene by CpG hypermethylation is associated with lung cancer. Biochem Biophys Res Commun 314: 223-228, 2004.

17. Xiao WH and Liu WW: Hemizygous deletion and hypermethylation of RUNX3 gene in hepatocellular carcinoma. World J Gastroenterol 10: 376-380, 2004.

18. Kato N, Tamura G, Fukase M, Shibuya H and Motoyama T: Hypermethylation of the RUNX3 gene promoter in testicular yolk sac tumor of infants. Am J Pathol 163: 387-391, 2003.

19. Goel A, Arnold CN, Tassone P, et al: Epigenetic inactivation of RUNX3 in microsatellite unstable sporadic colon cancers. Int $\mathrm{J}$ Cancer 112: 754-759, 2004.

20. Weersma RK, Zhou L, Nolte IM, et al: Runt-related transcription factor 3 is associated with ulcerative colitis and shows epistasis with solute carrier family 22 , members 4 and 5 . Inflamm Bowel Dis 14: 1615-1622, 2008 .

21. Brenner O, Levanon D, Negreanu V, Golubkov O, Fainaru O, Woolf E and Groner Y: Loss of RUNX3 function in leukocytes is associated with spontaneously developed colitis and gastric mucosal hyperplasia. Proc Natl Acad Sci USA 101: 16016-16021, 2004.
22. Lossos IS, Czerwinski DK, Alizadeh AA, Wechser MA, Tibshirani R, Botstein D and Levy R: Prediction of survival in diffuse large-B-cell lymphoma based on the expression of six genes. N Engl J Med 350: 1828-1837, 2004.

23. Chen HY, Yu SL, Chen CH, et al: A five-gene signature and clinical outcome in non-small-cell lung cancer. N Engl J Med 356: 11-20, 2007.

24. Watanabe T, Komuro Y, Kiyomatsu T, et al: Prediction of sensitivity of rectal cancer cells in response to preoperative radiotherapy by DNA microarray analysis of gene expression profiles. Cancer Res 66: 3370-3374, 2006.

25. Camós M, Esteve J, Jares P, et al: Gene expression profiling of acute myeloid leukemia with translocation $\mathrm{t}(8 ; 16)(\mathrm{p} 11 ; \mathrm{p} 13)$ and MYST3-CREBBP rearrangement reveals a distinctive signature with a specific pattern of HOX gene expression. Cancer Res 66: 6947-6954, 2006.

26. Livak KJ and Schmittgen TD: Analysis of relative gene expression data using real-time quantitative PCR and the 2(T) (-Delta Delta C) method. Methods 25: 402-408, 2001.

27. Fellermann K, Stange DE, Schaeffeler E, et al: A chromosome 8 gene-cluster polymorphism with low human beta-defensin 2 gene copy number predisposes to Crohn disease of the colon. Am J Hum Genet 79: 439-448, 2006.

28. Henrichsen CN, Chaignat E and Reymond A: Copy number variants, diseases and gene expression. Hum Mol Genet 18: R1-R8, 2009.

29. Lee JA, Carvalho CM and Lupski JR: A DNA replication mechanism for generating nonrecurrent rearrangements associated with genomic disorders. Cell 131: 1235-1247, 2007. 